\title{
Evapotranspiração do feijoeiro irrigado em plantio direto sobre diferentes palhadas de culturas de cobertura
}

\author{
Luís Fernando Stone ${ }^{(1)}$, Pedro Marques da Silveira ${ }^{(1)}$, José Aloísio Alves Moreira ${ }^{(1)}$ \\ e Antônio Joaquim Braga Pereira Braz ${ }^{(2)}$
}

\begin{abstract}
(1)Embrapa Arroz e Feijão, Caixa Postal 179, CEP 75375-000 Santo Antônio de Goiás, GO. E-mail: stone@cnpaf.embrapa.br, pmarques@cnpaf.embrapa.br, jaloisio@cnpaf.embrapa.br (2)Fundação de Ensino Superior de Rio Verde, Caixa Postal 104, CEP $75900-000$ Rio Verde, GO. E-mail: braga@fesurv.br
\end{abstract}

\begin{abstract}
Resumo - O objetivo deste trabalho foi determinar o efeito das palhadas de diferentes culturas de cobertura na evapotranspiração do feijoeiro irrigado cultivar Pérola. O experimento foi conduzido por dois anos, 2002/2003 e 2003/2004, na Embrapa Arroz e Feijão, em Santo Antônio de Goiás, GO, em Latossolo Vermelho distrófico, em delineamento de blocos ao acaso, com quatro repetições. No primeiro ano, os tratamentos consistiram de sete culturas de cobertura, conduzidas em plantio direto: braquiária (Brachiaria brizantha cv. Marandu); milho (Zea mays L.) consorciado com braquiária; guandu anão (Cajanus cajan (L.) Millisp); milheto (Pennisetum glaucum (L.) R. Br. cv. BN-2); mombaça (Panicum maximum cv. Mombaça); sorgo granífero (Sorghum bicolor (L.) Moench cv. BR 304); e estilosantes (Stylosanthes guianensis cv. Mineirão). No segundo ano, foi acrescentada a crotalária (Crotalaria juncea L.). A evapotranspiração, durante o ciclo do feijoeiro, foi determinada pela metodologia do balanço hídrico de campo e variou de 259,8 a 343,7 mm, dependendo da cultura de cobertura e do ano. As palhadas de braquiária e mombaça, pela maior produção de matéria seca, propiciaram as menores perdas de água por evapotranspiração. As maiores diferenças entre as palhadas das culturas de cobertura, com relação à evapotranspiração do feijoeiro, ocorrem nos estádios iniciais e finais do ciclo.
\end{abstract}

Termos para indexação: Phaseolus vulgaris, balanço hídrico do solo, drenagem, sonda de nêutrons.

\section{Evapotranspiration of irrigated common bean under no-tillage on different cover crop mulches}

\begin{abstract}
The objective of this work was to determine the effect of different cover crop mulches on the evapotranspiration of irrigated common bean cultivar Pérola. The experiment was carried out during two years, 2002/2003 and 2003/2004, at Embrapa Arroz e Feijão, in Santo Antônio de Goiás, GO, Brazil, on a Rhodic Haplustox, in a randomized block design, with four replications. In the first year, the treatments consisted of seven cover crops grown under no-tillage: Brachiaria brizantha cv. Marandu; corn (Zea mays L.) associated with B. brizantha; pigeon pea (Cajanus cajan (L.) Millisp); millet (Pennisetum glaucum (L.) R. Br. cv. BN-2); Panicum maximum cv. Mombaça; sorghum (Sorghum bicolor (L.) Moench cv. BR 304); and Stylosanthes guianensis cv. Mineirão. In the second year, it was added another cover crop, Crotalaria juncea L. The evapotranspiration during the common bean cycle was determined using the field water balance methodology, and it ranged from 259.8 to $343.7 \mathrm{~mm}$, depending on the cover crop and year. B. brizantha and P. maximum mulches, due to their highest dry weights, provided the lowest water losses through evapotranspiration. The highest differences among cover crops related to common bean evapotranspiration occurre in the initial and later stages of bean cycle.
\end{abstract}

Index terms: Phaseolus vulgaris, soil water balance, drainage, neutron probe.

\section{Introdução}

A formação e manutenção de cobertura morta é um dos principais entraves ao estabelecimento do plantio direto nos trópicos, onde as altas temperaturas, associadas à umidade adequada, promovem a decomposição rápida dos resíduos vegetais. A cobertura morta, resultante dos restos culturais de culturas anteriores e de plantas daninhas, geralmente é insuficiente para a plena cobertura do solo. Seguy et al. (1992) relataram que no Estado do Mato Grosso, no período de 90 dias após a primeira chuva, as palhadas de milho, arroz e soja tiveram sua matéria seca reduzida em 63, 65 e 86\%, respectivamente, e no fim deste período, 
promoveram cobertura do solo de 30,38 e $7 \%$. Lopes et al. (1987) observaram que 1 , 2 e 4 t ha $^{-1}$ de matéria seca de cobertura vegetal cobrem cerca de 20, 40 e $60-70 \%$ da superfície do solo, respectivamente. Acima de $7 \mathrm{t} \mathrm{ha}^{-1}$, a quase totalidade de superfície do solo é coberta. Pereira et al. (2002) obtiveram 25, 50, 75 e $100 \%$ de cobertura do solo com 2,25, 4,50, 6,75 e 9,00 tha ${ }^{-1}$ de palhada de Brachiaria decumbens.

A presença de palhada na superfície do solo, em quantidade adequada, é de grande importância na agricultura irrigada. Ela altera a relação solo-água, previnindo a evaporação e reduzindo a taxa de evapotranspiração das culturas, principalmente nos estádios em que o dossel destas não cobre totalmente o solo, o que resulta em redução na freqüência de irrigação e em economia nos custos de operação do sistema de irrigação.

Barros \& Hanks (1993) e Stone \& Moreira (2000) observaram maior eficiência do uso da água pelo feijoeiro no sistema plantio direto com cobertura morta, em relação a outros sistemas de preparo do solo. Esses autores verificaram, ainda, a economia de água em 14-30\%, dependendo do porte da planta. Pereira et al. (2002) observaram redução no número de irrigações feitas na cultura do feijoeiro e aumento do turno de rega, a partir de 50\% de cobertura da superfície do solo pela palhada. Esses autores e Andrade et al. (2002), ao comparar o efeito de diversas porcentagens de cobertura do solo pela palhada, sobre o consumo de água do feijoeiro em plantio direto, verificaram, respectivamente, que o tratamento de $100 \%$ de cobertura propiciou economia de água de 29 e 24\%, em relação ao tratamento sem cobertura.

O objetivo deste trabalho foi determinar o efeito da palhada de culturas de cobertura, na evapotranspiração do feijoeiro irrigado cultivado em sucessão, em sistema plantio direto.

\section{Material e Métodos}

O experimento foi conduzido por dois anos, 2002/2003 e 2003/2004, sob pivô central, na Fazenda Capivara, da Embrapa Arroz e Feijão, localizada no Município de Santo Antônio de Goiás, GO, em Latossolo Vermelho distrófico. As análises química e granulométrica iniciais do solo apresentaram os seguintes resultados: $\mathrm{pH}\left(\mathrm{H}_{2} \mathrm{O}\right)$, 5,7; $\mathrm{Ca}^{2+}, 20,5 \mathrm{mmol}_{\mathrm{C}} \mathrm{dm}^{-3} ; \mathrm{Mg}^{2+}, 7,4 \mathrm{mmol}_{\mathrm{C}} \mathrm{dm}^{-3} ; \mathrm{P}$, 21,5 mg dm${ }^{-3}$; K, $101 \mathrm{mg} \mathrm{dm}^{-3}$; matéria orgânica, $19 \mathrm{~g} \mathrm{dm}^{-3}$; areia, $490 \mathrm{~g} \mathrm{~kg}^{-1}$; silte, $270 \mathrm{~g} \mathrm{~kg}^{-1}$ e argila, $240 \mathrm{~g} \mathrm{~kg}^{-1}$. Foi utilizado o delineamento de blocos ao acaso, com quatro repetições. O tamanho das parcelas foi de 3,6 m de largura por $5 \mathrm{~m}$ de comprimento.
No primeiro ano, os tratamentos consistiram de sete culturas de cobertura: braquiária (Brachiaria brizantha cv. Marandu); milho (Zea mays L., híbrido HT BRS 3150) consorciado com braquiária; guandu anão (Cajanus cajan (L.) Millisp); milheto (Pennisetum glaucum (L.) R. Br., cv. BN-2); mombaça (Panicum maximum, cv. Mombaça); sorgo granífero (Sorghum bicolor (L.) Moench, cV. BR 304); e estilosantes (Stylosanthes guianensis cv. Mineirão). No segundo ano, foi acrescentada a crotalária (Crotalaria juncea L.).

As culturas de cobertura, no primeiro ano, foram semeadas no sistema plantio direto, em 3/12/2002, com exceção do consórcio milho e braquiária, que foi semeado em 3/1/2003. No segundo ano, todas as culturas de cobertura foram semeadas em 26/11/2003. O milho consorciado foi colhido em $17 / 4 / 2003$, no primeiro ano, e em 22/3/2004, no segundo ano. As coberturas foram moídas com triturador modelo triton, em 5/5/2003 e 23/3/2004, e secadas com glifosato (1,92 kg ha-1 de i.a.), em 24/6/2003 e 20/4/2004. No segundo ano, foi aplicado o dessecante paraquat $\left(0,2 \mathrm{~kg} \mathrm{ha}^{-1}\right.$ de i.a.), antes da semeadura do feijoeiro, que foi feita no sistema plantio direto, em 2/7/2003, no primeiro ano, e em 4/6/2004, no segundo ano, sobre as palhadas dessecadas, utilizando-se a cv. Pérola, no espaçamento de $0,45 \mathrm{~m}$, com 15 sementes por metro. A adubação foi de $400 \mathrm{~kg} \mathrm{ha}^{-1}$ da fórmula 4-30-16+Zn, no sulco, e $60 \mathrm{~kg} \mathrm{ha}^{-1}$ de $\mathrm{N}$, em cobertura, na forma de uréia.

A irrigação foi conduzida de maneira a manter, na camada de 0-0,3 m, o conteúdo de água do solo em valores próximos da capacidade de campo, o que corresponde ao potencial matricial de $-8 \mathrm{kPa}$. O controle da irrigação foi feito com o auxílio da curva de retenção da água do solo e da determinação diária da umidade. A umidade do solo foi determinada na camada de $0-0,2$ m e a cada $0,1 \mathrm{~m}$ de incremento de profundidade, até $0,6 \mathrm{~m}$, mediante o uso de uma sonda de nêutrons.

A evapotranspiração do feijoeiro, sob as diferentes palhadas das culturas de cobertura, foi determinada no período de 8 a 92 dias após a emergência (DAE), no primeiro ano, e no período de 8 a $99 \mathrm{DAE}$, no segundo ano, utilizando-se a metodologia do balanço hídrico de campo (Libardi \& Saad, 1994), considerando-se a profundidade de solo de $0,5 \mathrm{~m}$ :

$\mathrm{ETC}=\mathrm{P}+\mathrm{I} \pm \mathrm{D}-\mathrm{R}-\Delta \mathrm{A}$, em que: ETc é a evapotranspiração da cultura; P é a precipitação pluvial; I é a irrigação; D é a drenagem profunda ou ascensão capilar; R é o deflúvio superficial; 
e $\Delta \mathrm{A}$ é a variação do armazenamento, todos expressos em milímetros.

A precipitação e a irrigação foram registradas por coletores instalados no experimento. O deflúvio superficial foi considerado igual a zero, pois as irrigações foram feitas de maneira que não ocorresse escoamento, e as precipitações pluviais no período considerado foram poucas e de baixa intensidade.

O armazenamento de água no perfil do solo (A) foi calculado, integrando-se valores de conteúdo de água até $0,5 \mathrm{~m}$ de profundidade. A variação no armazenamento $(\Delta \mathrm{A})$ foi calculada pela diferença entre os armazenamentos $A_{2}$ e $A_{1}$, determinados nos tempos $t_{2}$ e $t_{1}$, expressos em dia.

Para o cálculo da drenagem interna, ou ascensão capilar, foi utilizada a equação de fluxo de BuckinghamDarcy:

$\mathrm{q}_{\mathrm{z}}=-\mathrm{K}(\theta) \mathrm{d} \Phi / \mathrm{dz}$,

em que: $q_{z}$ é a densidade de fluxo da água no solo, $\mathrm{mm} \mathrm{dia}{ }^{-1} ; K(\theta)$ é a condutividade hidráulica do solo em função da umidade $\theta, \mathrm{mm} \mathrm{dia}^{-1}$; e $\mathrm{d} \Phi / \mathrm{dz}$ é o gradiente de potencial total da água do solo, $\mathrm{m} \mathrm{m}^{-1}$.

Foi determinada a curva de retenção da água do solo, para a camada de 0,4-0,6 m, e feito o ajuste dos dados ao modelo de Van Genuchten (1980), expresso pela equação:

$\theta=\theta_{\mathrm{r}}+\left(\theta_{\mathrm{s}}-\theta_{\mathrm{r}}\right) /\left[1+(\alpha|\Phi \mathrm{m}|)^{\mathrm{n}}\right]^{\mathrm{m}}$,

em que: $\theta$ é o conteúdo de umidade do solo, $\mathrm{cm}^{3} \mathrm{~cm}^{-3}$; $\theta_{\mathrm{r}}$ é o conteúdo residual de umidade do solo, $\mathrm{cm}^{3} \mathrm{~cm}^{-3}$; $\theta_{\mathrm{s}}$ é o conteúdo saturado de umidade do solo, $\mathrm{cm}^{3} \mathrm{~cm}^{-3}$; $\Phi \mathrm{m}$ é o potencial matricial da água do solo, $\mathrm{kPa}$; $\mathrm{n}$ e $\mathrm{m}$ (m = $1-1 / n$ ) são parâmetros empíricos adimensionais de ajuste; e $\alpha$ é um parâmetro empírico de ajuste, $\mathrm{kPa}^{-1}$. Os valores dos parâmetros de ajuste foram: $\theta_{\mathrm{r}}=0,266 \mathrm{~cm}^{3} \mathrm{~cm}^{-3}, \quad \theta_{\mathrm{s}}=0,489 \mathrm{~cm}^{3} \mathrm{~cm}^{-3}$, $\alpha=0,8853 \mathrm{kPa}^{-1}, \mathrm{n}=1,4611$, e $\mathrm{m}=0,3156$, com $\mathrm{R}^{2}=0,999$.

A condutividade hidráulica do solo foi obtida pela equação apresentada em Loyola \& Prevedello (2003):

$\mathrm{K}(\theta)=\mathrm{K}_{\mathrm{s}}\left[\left(\theta-\theta_{\mathrm{r}}\right) /\left(\theta_{\mathrm{s}}-\theta_{\mathrm{r}}\right)\right]^{0,5}\left\{1-\left[1-\left[\left(\theta-\theta_{\mathrm{r}}\right) /\right.\right.\right.$ $\left.\left.\left.\left(\theta_{\mathrm{s}}-\theta_{\mathrm{r}}\right)\right]^{1 / \mathrm{m}}\right]^{\mathrm{m}}\right\}^{2}$,

em que: $K_{s}$ é a condutividade hidráulica saturada do solo, $\mathrm{mm} \mathrm{dia}{ }^{-1}$. O valor de $\mathrm{K}_{\mathrm{s}}, 1.800 \mathrm{~mm} \mathrm{dia}^{-1}$, foi obtido em laboratório, a partir de amostras indeformadas coletadas no campo, segundo metodologia apresentada em Embrapa (1997).

O potencial total foi determinado pela soma do potencial matricial com o potencial gravitacional. O potencial matricial foi determinado pela equação (3), com base na umidade do solo determinada nas profundidades 0,4 e $0,6 \mathrm{~m}$. O gradiente de potencial total da água do solo foi determinado pelo quociente da diferença dos potenciais totais a 0,4 e $0,6 \mathrm{~m}$, pela diferença entre estas profundidades $(0,2 \mathrm{~m})$.

A drenagem ou ascensão capilar foi determinada mediante o produto da condutividade hidráulica a $0,5 \mathrm{~m}$ de profundidade, pelo gradiente de potencial total da água do solo, entre as profundidades de 0,4 e 0,6 m.

No segundo ano, foi determinada a massa da matéria seca das culturas de cobertura, em $0,5 \mathrm{~m}^{2}$ por parcela, antes da semeadura e na colheita do feijoeiro, mediante o uso de um quadro amostrador de 0,5x1,0 m, lançado ao acaso sobre as parcelas. A palhada dentro do quadro foi retirada, secada em estufa com ventilação forçada a $65^{\circ} \mathrm{C}$, por 72 horas, até alcançar massa constante.

Os dados de evapotranspiração da cultura, drenagem, ascensão capilar e variação do armazenamento foram submetidos à análise de variância, e as médias foram comparadas pelo teste de Tukey a 5\% de probabilidade.

\section{Resultados e Discussão}

As lâminas totais de água aportadas à cultura do feijoeiro foram de 460,4 e 437,7 mm, no primeiro e no segundo ano, respectivamente (Figura 1 e Tabela 1). No último ano, apesar de as baixas temperaturas terem alongado o ciclo do feijoeiro (99 dias contra 92 no primeiro ano), a mais baixa demanda evaporativa da atmosfera fez com que a necessidade de água fosse menor. Essas lâminas estão condizentes com as relatadas por Guerra et al. (2000) e Rocha et al. (2003), de 450 e $460 \mathrm{~mm}$, respectivamente, para a semeadura em junho, em Planaltina, DF, sob preparo convencional do solo, com reinício da irrigação quando o potencial matricial da água do solo a $0,1 \mathrm{~m}$ atingia $-40 \mathrm{kPa}$. Entretanto, elas foram excessivas para as condições do presente estudo, em sistema plantio direto e com cobertura morta. Como relatado anteriormente, em razão da condução de vários experimentos no local, a irrigação foi conduzida de maneira que o conteúdo de água do solo, na camada de 0-0,3 m, se aproximasse da capacidade de campo, o que corresponde ao potencial matricial de $-8 \mathrm{kPa}$. Entretanto, para o feijoeiro sob plantio direto, é recomendado reiniciar a irrigação quando o potencial matricial da água do solo, a 0,15 m de profundidade, se encontrar próximo de -35 kPa (Moreira et al., 1998).

No primeiro ano, o menor valor de evapotranspiração do feijoeiro ocorreu sob a palhada de braquiária. Esse re- 
sultado foi confirmado no segundo ano, embora, nesse ano, não tenha diferido significativamente da palhada de mombaça (Tabela 1). Os maiores valores de evapotranspiração, por sua vez, ocorreram sob palhadas de estilosantes e de milho consorciado com braquiária, no primeiro ano, e sob palhadas de guandu, estilosantes e sorgo, no segundo ano. Esses valores estão relacionados com as
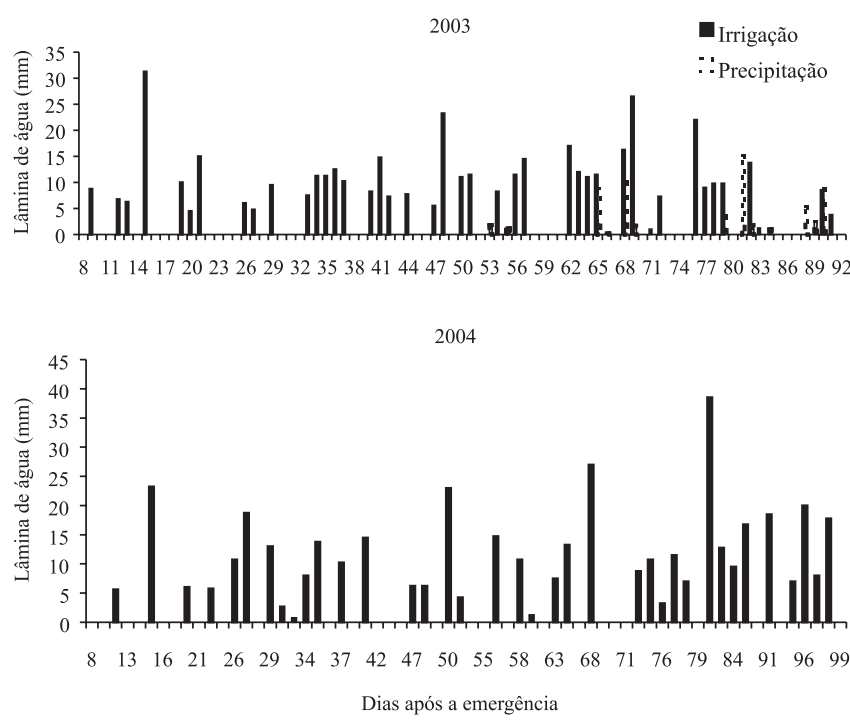

Figura 1. Lâminas de água aplicadas por irrigação e precipitação pluvial ocorrida durante o ciclo do feijoeiro, em 2003 e 2004. quantidades de matéria seca fornecidas pelas culturas de cobertura e com suas respectivas taxas de decomposição.

Com base nas equações de decomposição das palhadas desenvolvidas por Braz (2003), que estudou as mesmas culturas de cobertura, na mesma área experimental, estimou-se que no primeiro ano os valores de massa da matéria seca, aos oito dias após a dessecação - época da semeadura do feijoeiro -, seriam 11,8, 3,7, 5,2, 5,8, 7,3, 6,0 e 3,2 t ha-1 , para braquiária, milho consorciado com braquiária, guandu, milheto, mombaça, sorgo e estilosantes, respectivamente. Aos 92 dias após a emergência do feijoeiro, esses valores seriam iguais a 7,4 2,2, 2,5, 3,1, 3,4, 1,9 e 1,3 $\mathrm{t} \mathrm{ha}^{-1}$, respectivamente. O baixo valor de massa de matéria seca da braquiária consorciada com milho possivelmente ocorreu por causa da competição entre as culturas do milho e da braquiária, em que esta última só teve maior desenvolvimento após a colheita do milho, como constatou Braz (2003).

No segundo ano, a massa da matéria seca medida antes da semeadura do feijoeiro foi de 10,2, 4,9, 2,0, 7,4, 9,2, 3,2, 2,0 e 6,9 t ha-1 ${ }^{-1}$ respectivamente, para braquiária, milho consorciado com braquiária, guandu, milheto, mombaça, sorgo, estilosantes e crotalária; e na colheita do feijoeiro, esses valores foram iguais a 6,7, 3,4, 1,0, $4,4,5,4,1,5,1,2$ e $3,1 \mathrm{t} \mathrm{ha}^{-1}$, respectivamente. A relação entre a massa da matéria seca da palhada das culturas

Tabela 1. Componentes do balanço hídrico do feijoeiro, em mm, em função das palhadas das culturas de cobertura(1).

\begin{tabular}{|c|c|c|c|c|c|c|}
\hline Cultura de cobertura & $\begin{array}{l}\text { Precipitação } \\
\text { pluvial }\end{array}$ & Irrigação & $\begin{array}{c}\text { Evapotranspiração } \\
\text { da cultura }\end{array}$ & Drenagem & $\begin{array}{l}\text { Ascensão } \\
\text { capilar }\end{array}$ & $\begin{array}{c}\text { Variação do } \\
\text { armazenamento }\end{array}$ \\
\hline & \multicolumn{6}{|c|}{ Ano 2003} \\
\hline Braquiária & 62,1 & 398,3 & $265,5 d$ & $214,4 a$ & $0,0 \mathrm{a}$ & $-19,5 \mathrm{a}$ \\
\hline Milho + braquiária & 62,1 & 398,3 & $325,2 \mathrm{a}$ & $153,4 d$ & $5,7 \mathrm{a}$ & $-12,5 a$ \\
\hline Guandu & 62,1 & 398,3 & $307,6 \mathrm{~b}$ & $165,7 \mathrm{c}$ & $3,8 \mathrm{a}$ & $-9,1 \mathrm{a}$ \\
\hline Milheto & 62,1 & 398,3 & $304,7 b$ & $168,9 \mathrm{c}$ & $2,8 \mathrm{a}$ & $-10,4 a$ \\
\hline Mombaça & 62,1 & 398,3 & $285,8 \mathrm{c}$ & $185,7 b$ & $0,3 \mathrm{a}$ & $-10,8 \mathrm{a}$ \\
\hline Sorgo & 62,1 & 398,3 & $304,8 b$ & $170,3 \mathrm{c}$ & $3,2 \mathrm{a}$ & $-11,5 a$ \\
\hline Estilosantes & 62,1 & 398,3 & $334,9 a$ & $144,8 \mathrm{~d}$ & $5,9 \mathrm{a}$ & $-13,4 a$ \\
\hline \multirow[t]{2}{*}{$\mathrm{CV}(\%)$} & & & 1,7 & 3,1 & 80,1 & 42,1 \\
\hline & \multicolumn{6}{|c|}{ Ano 2004} \\
\hline Braquiária & 0 & 437,7 & $259,8 \mathrm{~d}$ & $189,4 \mathrm{a}$ & $15,7 \mathrm{~b}$ & $4,2 \mathrm{a}$ \\
\hline Milho + braquiária & 0 & 437,7 & $300,9 b$ & $154,5 \mathrm{bc}$ & $17,1 b$ & $-0,6 a$ \\
\hline Guandu & 0 & 437,7 & $343,7 \mathrm{a}$ & $137,2 \mathrm{c}$ & $40,3 \mathrm{a}$ & $-2,9 a$ \\
\hline Milheto & 0 & 437,7 & $277,1 \mathrm{c}$ & $174,9 \mathrm{ab}$ & $15,0 \mathrm{~b}$ & $0,7 \mathrm{a}$ \\
\hline Mombaça & 0 & 437,7 & $263,3 d$ & $188,0 \mathrm{a}$ & $14,6 \mathrm{~b}$ & $1,0 \mathrm{a}$ \\
\hline Sorgo & 0 & 437,7 & $332,6 \mathrm{a}$ & $133,6 \mathrm{c}$ & $30,3 \mathrm{ab}$ & $1,8 \mathrm{a}$ \\
\hline Estilosantes & 0 & 437,7 & $341,9 \mathrm{a}$ & $131,0 \mathrm{c}$ & $34,9 \mathrm{a}$ & $-0,3 a$ \\
\hline Crotalária & 0 & 437,7 & $293,8 b$ & $162,6 b$ & $18,5 \mathrm{~b}$ & $-0,2 \mathrm{a}$ \\
\hline CV (\%) & & & 1,8 & 6,3 & 29,2 & 318,0 \\
\hline
\end{tabular}

${ }^{(1)}$ Em cada coluna, médias seguidas pela mesma letra não diferem, significativamente, a 5\% de probabilidade pelo teste de Tukey. 
de cobertura, presente na semeadura e na colheita do feijoeiro, e a evapotranspiração desta cultura, no segundo ano, é apresentada na Figura 2. Verifica-se que a evapotranspiração foi proporcional tanto à quantidade de matéria seca presente no momento da semeadura do feijoeiro, como à presente por ocasião da sua colheita, indicando que o efeito da cobertura do solo se dá ao longo de todo o ciclo do feijoeiro. Considerando-se os resultados apresentados por Pereira et al. (2002), estimou-se que a braquiária solteira e o mombaça proporcionaram, durante o ciclo do feijoeiro, cobertura do solo entre 100 e $74 \%$, e entre 100 e $60 \%$, respectivamente.

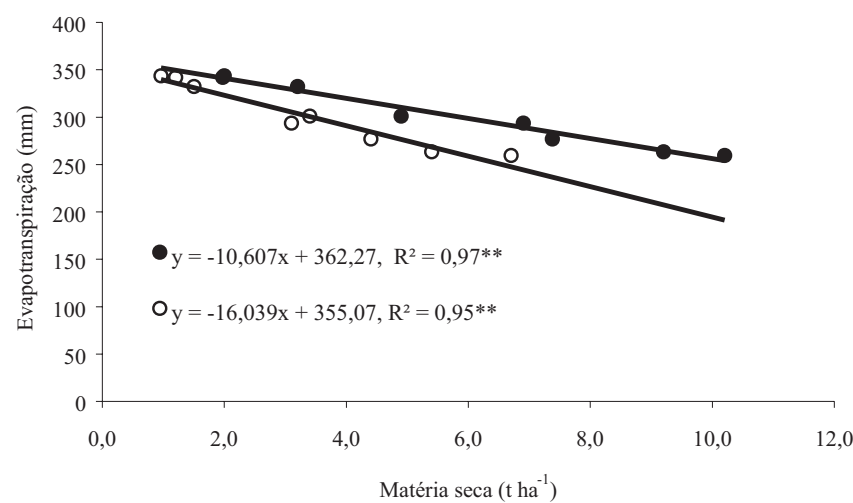

Figura 2. Evapotranspiração durante o ciclo do feijoeiro, em 2004, em função da massa da palhada das culturas de cobertura, determinada na semeadura (•) e na colheita (o) do feijoeiro.
O estilosantes, por sua vez, proporcionou uma cobertura entre 22 e $13 \%$, e o guandu, entre 22 e $11 \%$.

A ascensão capilar foi muito pequena, no primeiro ano, e ocorreu principalmente no final do ciclo do feijoeiro, não tendo havido diferenças entre as culturas de cobertura. No segundo ano, a ascensão capilar ocorreu, principalmente, no período entre 36 e 57 dias após a emergência do feijoeiro, tendo sido maior para as coberturas de guandu e estilosantes (Tabela 1).

As perdas de água por drenagem, no primeiro ano, variaram de 31,4\% do total da água aplicada por irrigação e precipitação pluvial, no caso da cobertura de estilosantes, a 46,6\%, na cobertura de braquiária solteira. No segundo ano, elas foram similares em termos porcentuais, tendo variado de 29,9 a 43,3\%, para essas mesmas coberturas (Tabela 1). Estes valores são bem altos, em razão da maneira como foi conduzida a irrigação. Libardi \& Saad (1994) relataram que a drenagem, em uma cultura de feijoeiro irrigada adequadamente, correspondeu a 9,6\% da quantidade de água aplicada por irrigação.

As diferenças entre as coberturas que proporcionaram os menores e os maiores valores de evapotranspiração do feijoeiro foram maiores nos estádios iniciais e finais, em que as plantas do feijoeiro cobriam menos o solo (Tabela 2). Entre os estádios V2 e o início de V4, no primeiro ano, a cobertura de braquiária proporcionou redução de $28 \%$ na

Tabela 2. Média diária da evapotranspiração, em mm, em diferentes estádios do ciclo do feijoeiro, em função das palhadas das culturas de cobertura.

\begin{tabular}{|c|c|c|c|c|c|c|c|c|c|}
\hline Estádio $^{(1)}$ & Duração (dia) & Braquiária & $\begin{array}{c}\text { Milho } \\
+ \text { braquiária }\end{array}$ & Guandu & Milheto & Mombaça & Sorgo & Estilosantes & Crotalária \\
\hline & \multicolumn{9}{|c|}{ Ano 2003} \\
\hline V2-V3 & 7 & 2,1 & 2,8 & 2,5 & 2,5 & 2,2 & 2,4 & 2,9 & - \\
\hline V3-V4 & 7 & 2,1 & 2,8 & 2,5 & 2,5 & 2,2 & 2,4 & 2,9 & - \\
\hline V4-R5 & 14 & 3,1 & 3,6 & 3,4 & 3,4 & 3,2 & 3,3 & 3,7 & - \\
\hline R5-R6 & 7 & 5,1 & 5,6 & 5,4 & 5,4 & 5,2 & 5,4 & 5,7 & - \\
\hline R6-R7 & 7 & 5,3 & 5,9 & 5,7 & 5,7 & 5,5 & 5,7 & 6,0 & - \\
\hline R7-R8 & 7 & 4,1 & 4,7 & 4,6 & 4,5 & 4,3 & 4,5 & 4,9 & - \\
\hline R8-R9 & 21 & 3,1 & 3,9 & 3,7 & 3,6 & 3,4 & 3,7 & 4,1 & - \\
\hline R9 & 15 & 1,8 & 2,7 & 2,5 & 2,4 & 2,2 & 2,5 & 2,8 & - \\
\hline \multicolumn{10}{|c|}{ Ano 2004} \\
\hline V2-V3 & 8 & 1,3 & 1,6 & 2,0 & 1,3 & 1,3 & 1,9 & 2,0 & 1,4 \\
\hline V3-V4 & 8 & 1,5 & 1,7 & 2,1 & 1,5 & 1,5 & 2,0 & 2,1 & 1,6 \\
\hline V4-R5 & 17 & 3,1 & 3,2 & 3,4 & 3,1 & 3,1 & 3,4 & 3,4 & 3,2 \\
\hline R5-R6 & 9 & 4,9 & 5,0 & 5,2 & 4,9 & 4,9 & 5,1 & 5,2 & 5,0 \\
\hline R6-R7 & 7 & 4,1 & 4,6 & 5,1 & 4,3 & 4,1 & 4,9 & 5,1 & 4,5 \\
\hline R7-R8 & 7 & 3,8 & 4,3 & 4,8 & 4,0 & 3,8 & 4,6 & 4,7 & 4,2 \\
\hline R8-R9 & 21 & 2,3 & 3,0 & 3,6 & 2,6 & 2,4 & 3,4 & 3,5 & 2,9 \\
\hline R9 & 15 & 2,5 & 3,4 & 4,1 & 3,0 & 2,7 & 3,9 & 4,1 & 3,3 \\
\hline
\end{tabular}

(1)V2: folhas primárias; V3: primeira folha trifoliada; V4: terceira folha trifoliada; R5: pré-floração; R6: início da floração; R7: formação das vagens; R8: enchimento das vagens; e R9: maturação fisiológica. 
evapotranspiração do feijoeiro, em comparação à de estilosantes. Nos estádios R8 e R9 esta redução foi, respectivamente, de 24 e $36 \%$. Nos demais estádios, a redução situou-se entre 11 e 16\%. No segundo ano, em comparação com a cobertura de guandu, a braquiária proporcionou reduções de 35 e $29 \%$, nos dois primeiros estádios, e de 36 e 39\%, nos dois últimos, respectivamente. Nos demais, as reduções variaram de 6 a $21 \%$.

\section{Conclusões}

1. As perdas de água por evapotranspiração, durante o ciclo do feijoeiro, dependem da quantidade de massa de matéria seca das culturas de cobertura, e são menores sobre palhadas de braquiária e mombaça.

2. As maiores diferenças entre as culturas de cobertura, com relação à evapotranspiração do feijoeiro, ocorrem nos estádios iniciais e finais do ciclo desta cultura.

\section{Referências}

ANDRADE, R. da S.; MOREIRA, J.A.A.; STONE, L.F.; CARVALHO, J. de A. Consumo relativo de água do feijoeiro no plantio direto em função da porcentagem de cobertura morta do solo. Revista Brasileira de Engenharia Agrícola e Ambiental, v.6, p.35-38, 2002.

BARROS, L.C.G.; HANKS, R.J. Evapotranspiration and yield of beans as affected by mulch and irrigation. Agronomy Journal, v.85, p.692-697, 1993.

BRAZ, A.J.B.P. Fitomassa e decomposição de espécies de cobertura do solo e seus efeitos na resposta do feijoeiro e do trigo ao nitrogênio. 2003. 72p. Tese (Doutorado) - Universidade Federal de Goiás, Goiânia.
EMBRAPA. Serviço Nacional de Levantamento e Conservação de Solos (Rio de Janeiro, RJ). Manual de métodos de análise de solos. 2.ed. Rio de Janeiro, 1997. 212p.

GUERRA, A.F.; SILVA, D.B. da; RODRIGUES, G.C. Manejo de irrigação e fertilização nitrogenada para o feijoeiro na Região dos Cerrados. Pesquisa Agropecuária Brasileira, v.35, p.1229-1236, 2000.

LIBARDI, P.L.; SAAD, A.M. Balanço hídrico em cultura de feijão irrigada por pivô central em Latossolo Roxo. Revista Brasileira de Ciência do Solo, v.18, p.529-532, 1994.

LOPES, P.R.C.; COGO, N.P.; LEVIEN, R. Eficácia relativa de tipo e quantidade de resíduos culturais espalhados uniformemente sobre o solo na redução da erosão hídrica. Revista Brasileira de Ciência do Solo, v.11, p.71-75, 1987.

LOYOLA, J.M.T.; PREVEDELLO, C.L. Modelos analíticos para predição do processo da redistribuição da água no solo. Revista Brasileira de Ciência do Solo, v.27, p.783-787, 2003.

MOREIRA, J.A.A.; STONE, L.F.; SILVEIRA, P.M. da. Manejo da irrigação do feijoeiro em plantio direto: tensão da água do solo. Santo Antônio de Goiás: Embrapa-CNPAF, 1998. 2p. (EmbrapaCNPAF. Pesquisa em foco, 13).

PEREIRA, A.L.; MOREIRA, J.A.A.; KLAR, A.E. Efeito de níveis de cobertura do solo sobre o manejo da irrigação do feijoeiro (Phaseolus vulgaris L.). Irriga, v.7, p.42-52, 2002.

ROCHA, O.C.; GUERRA, A.F.; AZEVEDO, H.M. de. Ajuste do modelo Chistiansen-Hargreaves para estimativa da evapotranspiração do feijão no Cerrado. Revista Brasileira de Engenharia Agrícola e Ambiental, v.7, p.263-268, 2003.

SEGUY, L.; BOUZINAC, S.R.R.; MATSUBARA, M. Gestão do solo e das culturas nas fronteiras agrícolas dos cerrados úmidos do Centro-Oeste. Lucas do Rio Verde: RAP/CIRAD-CA/Fazenda Progresso, 1992. 107p.

STONE, L.F.; MOREIRA, J.A.A. Efeitos de sistemas de preparo do solo no uso da água e na produtividade do feijoeiro. Pesquisa Agropecuária Brasileira, v.35, p.835-841, 2000.

VAN GENUCHTEN, M.T. A closed-form equation for predicting the hydraulic conductivity of unsaturated soils. Soil Science Society of America Journal, v.44, p.892-898, 1980. 